\title{
ON SOME GENERALIZATIONS OF ENESTRÖM-KAKEYA THEOREM
}

\author{
NISAR A. RATHER
}

Abstract. In this paper, we obtain some generalizations of a well-known result of EneströmKakeya concerning the bounds for the moduli of the zeros of polynomials with complex coefficients which improve some known results.

Mathematics subject classification (2010): 26C10, 30C15.

Keywords and phrases: Zeros, polynomials, complex domain.

\section{REFERENCES}

[1] C. Affane-Aji, N. Agarwal And N. K. Govil, Location of zeros of polynomials, Mathematival and Computer Modelling, 50 (2009), 306-313.

[2] C. AfFANE-AJi AND N. K. GoviL, On the regions containing all the zeros of a polynomial, Nonlinear Analysis: Stability, Approximation and Inequalities, Edited by P. G. Georgiev, P. Pardalos and H. M. Srivastava, Springer, Optimization and its Applications, 68 (2012), 39-55.

[3] N. Anderson, E. B. SAFF, R. S. VARGA,On the Eneström-Kakeya theorem and its sharpness, Linear Algebra Appl., 28 (1979), 5-16.

[4] N. Anderson, E. B. SAFF, R. S. VARGA, An extension of the Eneström-Kakeya theorem and its sharpness, SIAM J. Math. Anal., 12 (1981), 10-22.

[5] A. AZIZ AND Q. G. Mohammad, Zero free regions for polynomials and some generalizations of Eneström-Kakeya theorem, Canad. Math. Bull., 27(3) (1984), 265-272.

[6] A. AZIZ AND W. M. Shah, On the zeros of polynomial and related analytic functions, Glas. Mat., 3(53) (1998), 173-184.

[7] A. Aziz And B. A Zargar, Some extensions of Eneström-Kakeya theorem, Glas. Mat., 33 (1996), 239-244.

[8] A. AZIZ AND B. A ZARGAR, Bounds for the zeros of a polynomial with restricted coefficients, Appl. Math., 3 (2012), 3-33.

[9] J. CAO AND R. GARDNER, Restrictions on the zeros of as a consequence of conditions on the coeffcients of even powers and odd powers of the variable, J. Comput. Appl. Math, 155 (2003), 153-163.

[10] A. CAUCHY, Exercises de mathématique, Oeuvres, (2) Volume 9, p. 122 (1829).

[11] G. T. CARGO AND O. SHISHA, Zeros of polynomials and fractional order differences of their coefficients, J. Math. Anal. Appl., 7 (1963) 176-182.

[12] Y. Choo And G. K. CHOI, On the robustness property of Eneström-Kakeya theorem, Int. J. Math. Anal., 5(42) (2011), 2089-2096.

[13] K. K. Dewan and M. Bidkham, On the Eneström-Kakeya theorem, J. Math. Anal. Appl., 180 (1993), 29-36.

[14] R. B. GARDNER AND N. K. GoviL, Some generalizations of Eneström-Kakeya theorem, Acta Math. Hungar., 74(1-2) (1997), 125-134.

[15] R. B. GARDNER AND N. K. GoviL, The Eneström-Kakeya theorem and some of its generalizations, in S. Joshi, M. Dorff and I. Lahiri(Eds), Current Topics in Pure and Computational Complex Analysis, New Delhi; Springer- Verlag (2014), 171-200.

[16] M. Kovačević And I. Milovanović, On a generalization of the Eneström-Kakeya theorem, Pure Math. and Applic. Ser. A, 3 (1992), 543-547.

[17] V. K. Jain, On the zeros of polynomials, Proc. Indian Acad. Sci. Math. Sci., 119(1) (2009), 37-43.

[18] A. Joyal, G. Labelle AND Q. I. Rahman, On the locations of zeros of polynomials, Canad. Math. Bull., 10(1) (1967), 53-63. 
[19] P. V. Krishnaiah, On the Eneström-Kakeya theorem, J. London Math. Soc., 30 (1955) 314-19.

[20] A. Lin, B. HUANG, J. CAO, R. GARDNER, Some results on the location of zeros of analytic functions, Chinese J. Engrg. Math., 21(5) (2004), 785-791.

[21] M. Marden, Geometry of polynomials, Math. Surveys No. 3, Amer. Math. Soc., Providence R. I. 1966.

[22] G. V. Milovanović, D. S. Mitrinović And Th. M. Rassias, Topics in polynomials: extremal properties, inequalities, zeros, World scientific Publishing Co., Singapore, (1994).

[23] Q. I. Rahman And G. SchmeIsser, Analytic theory of polynomial, Clarendon Press, Oxford, 2002.

[24] N. A. Rather, S. Ahmad And M. I. Mir, On the Eneström-Kakeya theorem, Int. J. Pure Appl. Math., 41 (2007), 807-816.

[25] N. A. RATHER, S. AHMAD, A remark on generalizations of Eneström-Kakeya theorem, Math. Balkanica., 21, Fasc. 3-4(2007), 319-328. 